\title{
Correction to: Optimal Design and Feature Selection by Genetic Algorithm for Emotional Artificial Neural Network (EANN) in Rainfall-Runoff Modeling
}

\author{
Amir Molajou ${ }^{1} \cdot$ Vahid Nourani $^{2,3} \cdot$ Abbas Afshar $^{1} \cdot$ Mina Khosravi $^{1} \cdot$ Adam Brysiewicz $^{4}$
}

Published online: 15 June 2021

๑) Springer Nature B.V. 2021

\section{Correction to: Water Resour Manag.} https://doi.org/10.1007/s11269-021-02818-2

The original version of this article unfortunately contained a mistake. The second affiliation should be Center of Excellence in Hydroinformatics and Faculty of Civil Engineering, University of Tabriz, Tabriz, Iran. The original article has been corrected.

Publisher's Note Springer Nature remains neutral with regard to jurisdictional claims in published maps and institutional affiliations.

The original article can be found online at https://doi.org/10.1007/s11269-021-02818-2.

Amir Molajou

amolajou@yahoo.com

Vahid Nourani

vnourani@yahoo.com

Abbas Afshar

a_afshar@iust.ac.ir

Mina Khosravi

Mina.Khosravi1995@yahoo.com

Adam Brysiewicz

a.brysiewicz@itp.edu.pl

1 Department of Water Resources Eng, Faculty of Civil Eng, University of Science \& Technology, Tehran, Iran

2 Center of Excellence in Hydroinformatics, Faculty of Civil Engineering, University of Tabriz, Tabriz, Iran

3 Faculty of Civil and Environmental Engineering, Near East University, via Mersin 10, 99138 Nicosia, N Cyprus, Turkey

4 Institute of Technology and Life Sciences, Raszyn, Poland 